\title{
SEI Architecture Analysis Techniques and When to Use Them
}

CMU/SEI-2002-TN-005

Mario R. Barbacci

October 2002

Architecture Tradeoff Analysis Initiative 
The Software Engineering Institute is a federally funded research and development center sponsored by the U.S. Department of Defense.

Copyright (C) 2002 by Carnegie Mellon University.

\section{NO WARRANTY}

THIS CARNEGIE MELLON UNIVERSITY AND SOFTWARE ENGINEERING INSTITUTE MATERIAL IS FURNISHED ON AN “AS-IS” BASIS. CARNEGIE MELLON UNIVERSITY MAKES NO WARRANTIES OF ANY KIND, EITHER EXPRESSED OR IMPLIED, AS TO ANY MATTER INCLUDING, BUT NOT LIMITED TO, WARRANTY OF FITNESS FOR PURPOSE OR MERCHANTABILITY, EXCLUSIVITY, OR RESULTS OBTAINED FROM USE OF THE MATERIAL. CARNEGIE MELLON UNIVERSITY DOES NOT MAKE ANY WARRANTY OF ANY KIND WITH RESPECT TO FREEDOM FROM PATENT, TRADEMARK, OR COPYRIGHT INFRINGEMENT.

This work was created in the performance of Federal Government Contract Number F19628-00-C-0003 with Carnegie Mellon University for the operation of the Software Engineering Institute, a federally funded research and development center. The Government of the United States has a royalty-free governmentpurpose license to use, duplicate, or disclose the work, in whole or in part and in any manner, and to have or permit others to do so, for government purposes pursuant to the copyright license under the clause at 252.227-7013.

Internal use. Permission to reproduce this document and to prepare derivative works from this document for internal use is granted, provided the copyright and "No Warranty" statements are included with all reproductions and derivative works.

External use. Requests for permission to reproduce this document or prepare derivative works of this document for external and commercial use should be addressed to the SEI Licensing Agent.

Use of any trademarks in this report is not intended in any way to infringe on the rights of the trademark holder.

For information about purchasing paper copies of SEI reports, please visit the publications portion of our Web site (http://www.sei.cmu.edu/publications/pubweb.html). 


\section{Table of Contents}

Abstract $\ldots \ldots \ldots \ldots \ldots \ldots \ldots \ldots \ldots \ldots \ldots \ldots \ldots \ldots \ldots \ldots \ldots \ldots \ldots$

1 Introduction $\ldots \ldots \ldots \ldots \ldots \ldots \ldots \ldots \ldots \ldots \ldots \ldots \ldots \ldots \ldots$

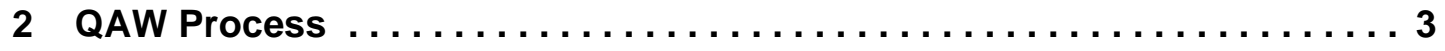

2.1 Scenario Generation $\ldots \ldots \ldots \ldots \ldots \ldots \ldots \ldots \ldots \ldots \ldots$

2.2 Architectural Test Case Development ................. 6

2.3 Architectural Test Case Analysis . . . . . . . . . . . . . . 7

2.4 Presentation of Results $\ldots \ldots \ldots \ldots \ldots \ldots \ldots \ldots \ldots \ldots$

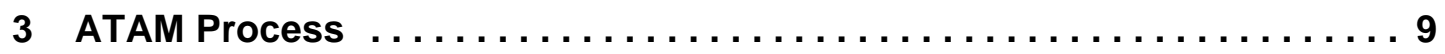

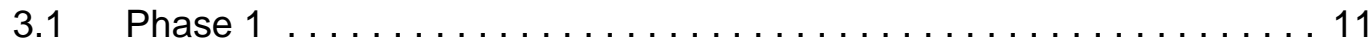

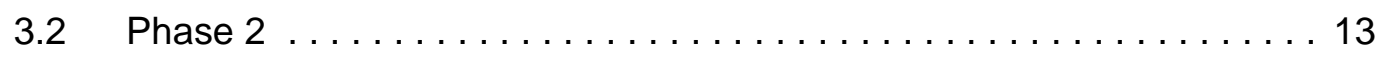

4 An Example Application of Both

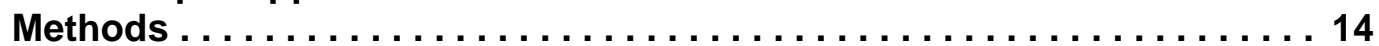

4.1 Activities During the Competitive Solicitation Phase . . . . . . . . . 14

4.2 Activities During the Competitive Fly-Off Phase . . . . . . . . . . . 16

4.3 Activities During the System Implementation Phase . . . . . . . . . . 17

5 Summary Comparison $\ldots \ldots \ldots \ldots \ldots \ldots \ldots \ldots \ldots \ldots \ldots \ldots \ldots \ldots \ldots$

References. . . . . . . . . . . . . . . . . . . . . . . . . 21 


\section{List of Figures}

Figure 1: QAW Process .................... 4

Figure 2: Example Illustration of Refined Scenario Issues and Questions . . . . . 7

Figure 3: ATAM Process. . . . . . . . . . . . . . . . . 10

Figure 4: Example ATAM Utility Tree . . . . . . . . . . . . . . . . . 12

Figure 5: A Common Acquisition Strategy [Bergey 02] . . . . . . . . . . 14

Figure 6: QAW Activities During the Competitive Solicitation Phase . . . . . . 15

Figure 7: QAW Activities During the Competitive Fly-Off Phase $\ldots \ldots \ldots \ldots 16$

Figure 8: ATAM Activities During the System Implementation Phase . . . . . . 18 


\section{List of Tables}

Table 1: Agenda for QAW Scenario Generation . . . . . . . . . . . 5

Table 2: Template for QAW Scenario Refinement $\ldots \ldots \ldots \ldots \ldots \ldots \ldots$

Table 3: QAW and ATAM Inputs, Outputs, and Participants for Various

Activities . . . . . . . . . . . . . . . . . . . . . . . . 19 


\section{Abstract}

The Software Engineering Institute $\left(\mathrm{SEI}^{\mathrm{SM}}\right)$ has developed two methods for analyzing system and software architectures - the Quality Attribute Workshop (QAW) and the Architecture Tradeoff Analysis Method ${ }^{\mathrm{SM}}\left(\mathrm{ATAM}^{\mathrm{SM}}\right)$. These techniques, which are described in detail in various SEI technical reports and on the SEI Web site, can be used in combination to obtain early and continuous benefits. Designed to complement the ATAM, the QAW provides a method for analyzing a conceptual architecture or a system architecture against a number of critical quality attributes - such as availability, performance, security, interoperability, and modifiability-before the software architecture is fully developed. Once the software architecture is developed, the ATAM can be used to reveal how well the architecture satisfies particular quality attribute requirements and the risks, sensitivities, and tradeoffs involved in satisfying the requirements.

The purpose of this technical note is to describe, using a hypothetical example, the alignment, combination, and uses of the two methods. 


\section{Introduction}

Quality Attribute Workshops (QAWs) provide a method for analyzing a system's architecture against a number of critical quality attributes — such as availability, performance, security, interoperability, and modifiability - that are derived from mission or business goals [Barbacci 02]. The QAW does not assume the existence of a software architecture. It was developed to complement the Architecture Tradeoff Analysis MethodSM (ATAMSM) 1 in response to customer requests for a method that identifies important quality attributes and clarifies system requirements before there is a software architecture to which the ATAM could be applied 2 [Kazman 00]. The QAW can be applied to a conceptual (or "notional") architecture or a system architecture. The QAW and the ATAM, which are described in detail in various Software Engineering Institute (SEISM) 3 technical reports, in the book Evaluating Software Architectures: Methods and Case Studies [Clements 01], and on the SEI Web site [SEI 02], can be used in combination to obtain early and continuous benefits. It should be noted that the SEI has developed related evaluation techniques, namely the Software Architecture Analysis Method (SAAM, a predecessor of the ATAM), Active Reviews for Intermediate Designs (ARID), and the Cost Benefit Analysis Method (CBAM), which are not covered in this technical note.

In an ATAM evaluation, an external team facilitates meetings between stakeholders during which scenarios representing the quality attributes of the system are developed, prioritized, and analyzed against the architectural approaches chosen for the system. Typical stakeholders include developers, users, maintainers, and buyers. The results of the analysis are expressed as risks, sensitivity points, and tradeoffs. To conduct an ATAM evaluation, an articulation of the business drivers and an initial draft of the software architecture are required. A typical ATAM evaluation would involve 2 two-to-three day meetings between the evaluation team and the stakeholders over the course of a few weeks.

The QAW involves similar activities earlier in the life cycle of a project. In the QAW, an external team facilitates meetings between stakeholders, during which scenarios representing quality attribute requirements are generated, prioritized, and refined (refining involves adding details about the personnel and assets required, the sequence of activities, and questions about

1 Architecture Tradeoff Analysis Method and ATAM are service marks of Carnegie Mellon University.

2 The ATAM was developed to evaluate a software architecture and has been technically validated for this purpose. Others have applied the ATAM to other types of architecture, but the SEI currently makes no claims about the ATAM's capabilities beyond the evaluation of a software architecture.

3

SEI is a service mark of Carnegie Mellon University. 
the requirements). After the scenario generation meeting(s), the refined scenarios are converted into architectural test cases that the architecture team analyzes against the system architecture. The architectural test case development and analysis often takes place over an extended period of time (perhaps months) before the architecture team presents the results of the analysis to the stakeholders.

The remainder of this technical note describes the QAW and the ATAM and uses a hypothetical example (based on a common United States government acquisition strategy) to illustrate when various QAW and ATAM activities are applicable. 


\section{QAW Process}

The QAW process shown in Figure 1 can be organized into four distinct groups of activities: (1) scenario generation, prioritization, and refinement, (2) architectural test case development, (3) analysis of test cases against the system architecture, and (4) presentation of the results.

The first and last activities of the process occur in facilitated, short meetings that last one or two days. The two middle activities take place offline and can continue over an extended period of time. Depending on the application context, the specific roles and responsibilities of the participants in the various activities can be customized [Barbacci 02].

The process is iterative in that the architectural test case analyses might lead to modifications of the architecture that, in turn, might prompt additional test case analyses that result in a continuous cycle of analyses and architectural modifications. ${ }^{4}$

This document describes the QAW method in generic terms. The actual application of the method can be tailored to the needs of a specific organization [Barbacci 02].

\subsection{Scenario Generation}

The first activity in the QAW process is to generate, prioritize, and refine scenarios. In this process, a scenario is a statement about some anticipated or potential use or behavior of the system; it captures stakeholders' concerns about how the system will do its job. The scenarios are generated during a facilitated brainstorming meeting of system stakeholders [Barbacci 02].

A typical agenda for this meeting is shown in Table 1. The meeting starts with a facilitation team's presentation of an overview of the QAW process, including QAW activities (the ovals in Figure 1) and their expected outcomes. A customer representative then describes the system's mission or business drivers, including the business context for the system, architectural drivers (quality attributes that "shape" the architecture), and critical requirements (quality attributes that are most central to the system's success). The presentation of the business drivers is followed by an overview of the system architecture. The overview addresses technical constraints (such as an operating system, hardware, or middleware prescribed for use), other

\footnotetext{
4 Figure 1 does not include planning activities such as planning the scenario generation meeting because these activities might require a number of interchanges.
} 


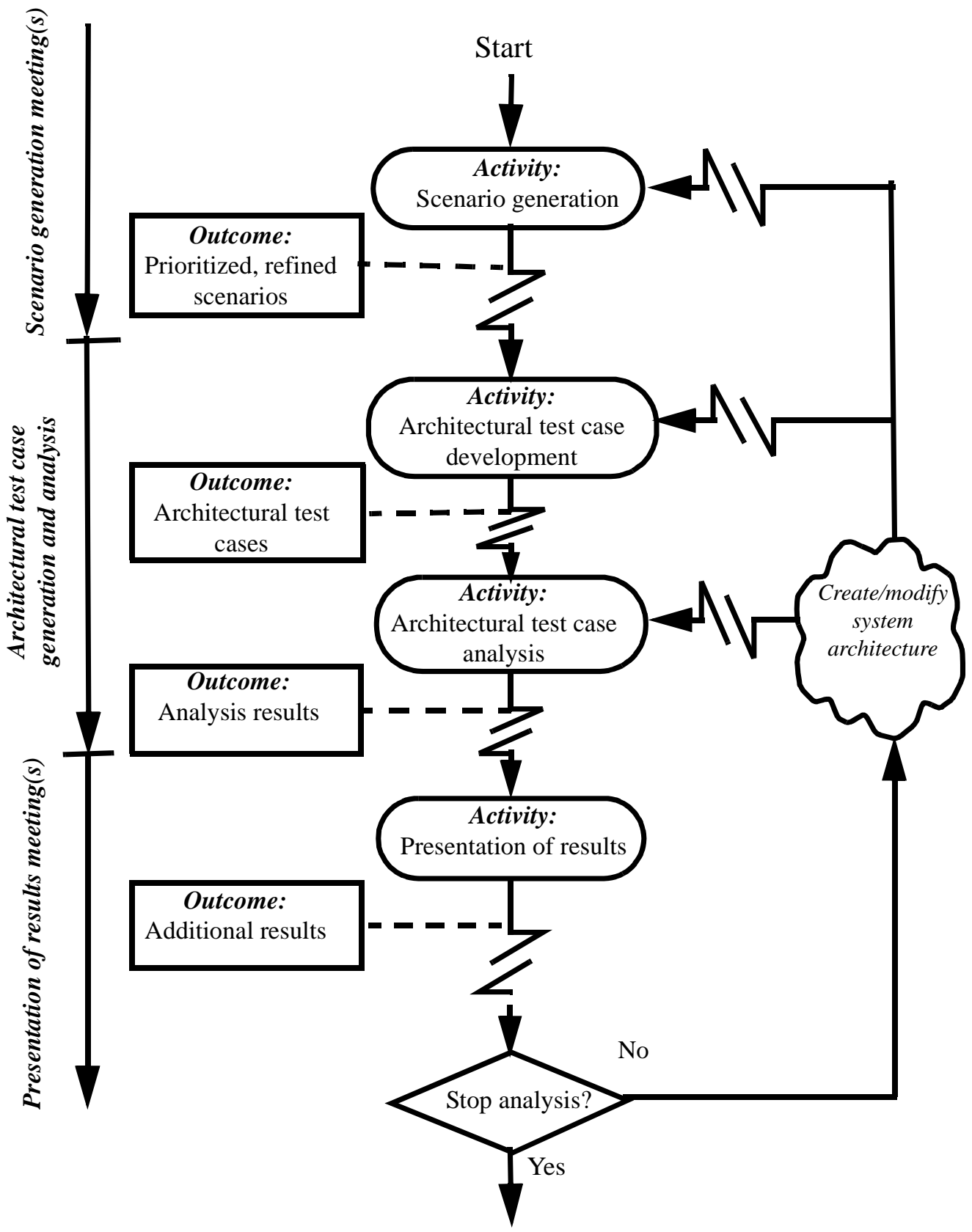

Figure 1: $\quad$ QAW Process 


\begin{tabular}{|l|l|}
\hline \multicolumn{1}{|c|}{ Time } & \multicolumn{1}{c|}{ Activity } \\
\hline 8:30 a.m. & $\begin{array}{l}\text { Start } \\
\text { Welcome and introductions } \\
\text { QAW overview } \\
\text { Business drivers } \\
\end{array}$ \\
& System architecture \\
\hline 10:00 a.m. & Scenario generation and prioritization \\
\hline Noon & Lunch break \\
\hline 1:00 p.m. & Scenario refinement \\
\hline 3:00 p.m. & Wrap-up \\
Review scenarios \\
4:00 p.m.
\end{tabular}

\section{Table 1: $\quad$ Agenda for QAW Scenario Generation}

systems with which the system will interact, and planned architectural approaches to address quality attribute requirements. 5 These three presentations set the context for the activities that follow.

Stakeholders are encouraged to generate as many scenarios as possible to represent a wide range of concerns. However, only a small number of scenarios can be refined during a one-day meeting. Thus, stakeholders must prioritize the scenarios generated previously by using a voting process; they must then refine the top three or four scenarios to provide a better understanding of them in terms of context and detail. Prior to voting, the stakeholders can merge scenarios that they consider to be closely related. The template shown in Table 2 illustrates the types of details that usually emerge from the refinement.

The result of this meeting is a prioritized list of scenarios and refined descriptions of the top three or four (merged) scenarios on that list.

5 Depending on the situation (e.g., a planned competitive acquisition vs. an internal corporate development), the system developers may or may not be participants in this meeting. If developers are excluded, the architecture presentation would be made by a customer representative and would describe desired rather than planned approaches. 


\begin{tabular}{|l|l|}
\hline Section & Content \\
\hline Reference Scenario(s) & $\begin{array}{l}\text { The scenario that is being refined is listed here. If it is a merged } \\
\text { scenario, the combined scenarios are listed here in their original } \\
\text { form. }\end{array}$ \\
\hline Organizations & Organizations involved in or affected by the scenario(s) \\
\hline Actors/Participants & Individuals involved in or affected by the scenario(s) \\
\hline Quntext & Quality attributes involved in or affected by the scenario(s) \\
\hline Questions & $\begin{array}{l}\text { A description of additional details such as the environment in } \\
\text { which the scenario takes place, and the sequence, frequency, and } \\
\text { duration of events }\end{array}$ \\
$\begin{array}{l}\text { Specific questions that the stakeholders would like to ask the } \\
\text { architect and the designers of the system. Typically one or more } \\
\text { questions are included for each quality attribute identified } \\
\text { above, for example } \\
\text { - How will the system prevent unauthorized users from } \\
\text { accessing the system? } \\
\text { - How will the system store one year of information online? } \\
\text { How will the system respond to user requests within 10 sec- } \\
\text { onds during peak time? }\end{array}$ \\
\hline
\end{tabular}

Table 2: $\quad$ Template for QAW Scenario Refinement

\subsection{Architectural Test Case Development}

The objective of developing architectural test cases is to transform each refined scenario from a statement and list of organizations, participants, quality attributes, and questions into a welldocumented architectural test case. Test cases may add assumptions and clarifications to the context, add or rephrase questions, group questions by topic, and so forth. The individual or team responsible for developing test cases depends on the situation. Barbacci and associates describe how the QAW method has been applied and who carried out the task (such as the sponsor/acquirer or development team) [Barbacci 02].

An architectural test case has a context section that outlines the important aspects of the case, an issues and questions section that states the stakeholders' concerns, and a graphical illustration that summarizes these issues and questions. Figure 2 provides a visual summary of the most important quality attributes and the specific issues and questions that pertain to the attributes. 


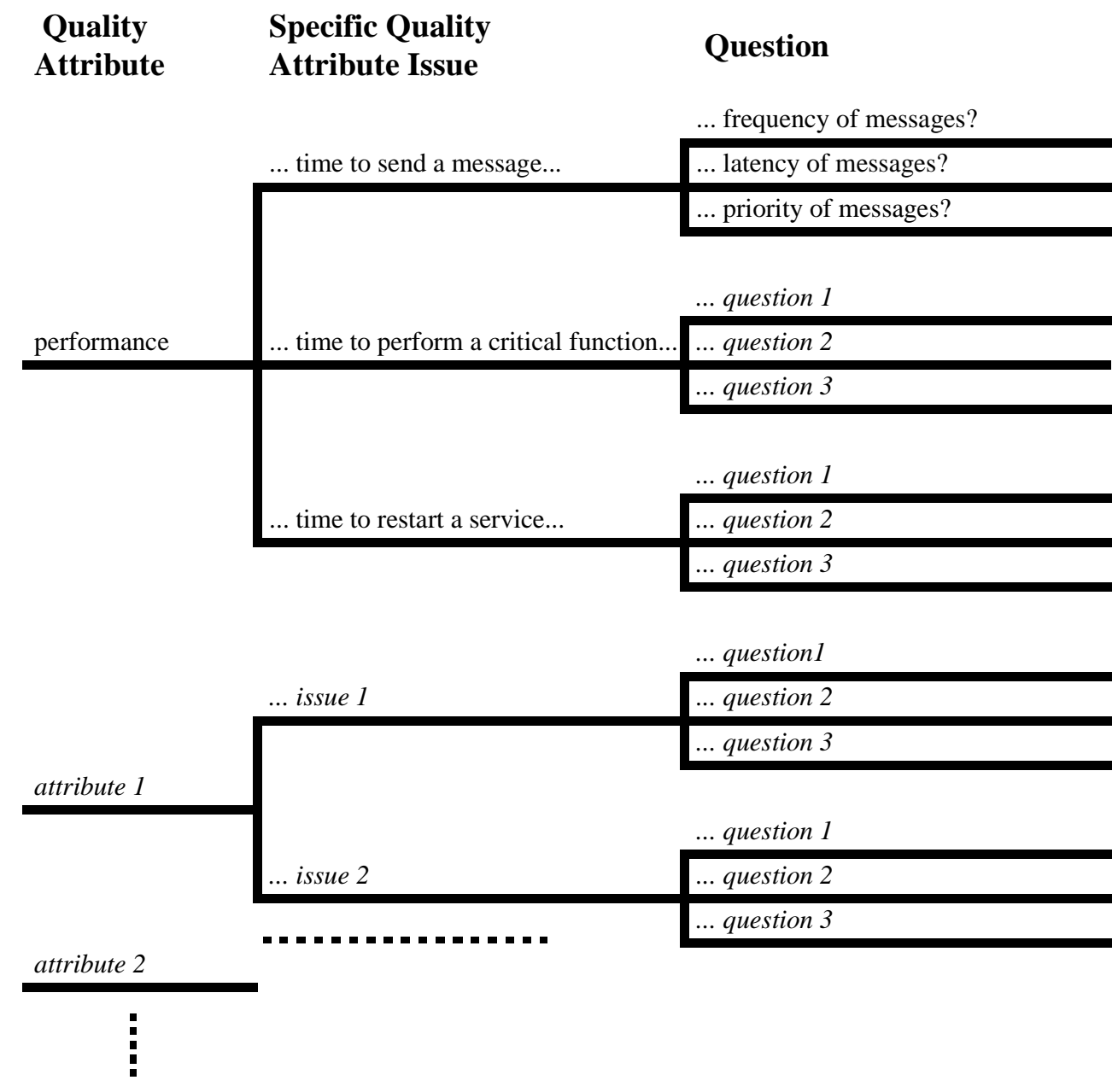

Figure 2: Example Illustration of Refined Scenario Issues and Questions

\subsection{Architectural Test Case Analysis}

Typical steps for conducting the architectural test case analysis include the following:

1. Review the capabilities of the assets in the test case context and determine how the system will react to the situation.

2. Make and document any assumptions necessary to proceed with the analysis.

3. Determine which architectural views (e.g., operational, system, technical, process, behavioral, structural) can best describe how the system will address the issues and their associated questions. 
4. Perform the analysis for the selected architectural test cases.

5. If necessary, refine the architecture to help answer the questions.

6. Document the answers as specifically as possible.

The analysis for a specific architectural test case would clarify or confirm specific quality attribute requirements and might identify concerns that would drive the development of the software architecture. Some of the test cases could later be used as "seed scenarios" in an ATAM evaluation (e.g., to check if a concern identified during the test case analysis was addressed by the software architecture). The results of analyzing a test case should be documented with specific architectural decisions, quality attribute requirements, and rationales.

\subsection{Presentation of Results}

The presentation is a one- or two-day facilitated meeting attended by the architecture team and other stakeholders. As the final activity in the QAW process, it provides an opportunity for the architecture team to present the results of their analysis and demonstrate that the proposed architecture is able to handle the architectural test cases correctly.

Prior to the meeting, participants are provided with a short document describing the QAW process, business drivers, and architectural plans that were presented during the scenario generation meeting. In addition, the document includes the original scenarios, the architectural test cases, and an example of a test case analysis. Ideally, the participants would be the same stakeholders who took part in the scenario generation meeting. However, since the presentation of results might take place a few months after the first meeting, there will likely be some participants who were not involved in the early meeting. The short document serves as a reminder to those participants who were involved in the scenario generation meeting and as an introduction to the QAW process for new participants.

The conclusions, recommendations, and action items resulting from the presentation must be captured in a short report to be distributed to the participants. The results might lead to modifications of the architecture, which, in turn, might lead to further analysis of test cases or even new test cases. These iterations are shown in Figure 1. 


\section{ATAM Process}

Since the ATAM is a few years more mature than the QAW, the ATAM process is more precisely defined and has been more rigorously validated. The ATAM process, shown in Figure 3, is organized into two main phases, each consisting of several steps. The steps in each phase usually take place during a one- to two-day facilitated meeting, while the two phases are usually a few weeks apart. 6

Phase 1 involves a small group of predominantly technically-oriented stakeholders. This phase is architecture-centric, focused on eliciting detailed architectural information and conducting a top-down analysis. Phase 2 involves a larger group of stakeholders. This phase is stakeholdercentric and focuses on eliciting points of view from diverse stakeholders and on verifying the results of Phase 1.

The ATAM involves nine steps:

1. Present the ATAM

2. Present business drivers

3. Present architecture

4. Identify architectural approaches

5. Generate quality attribute utility tree

6. Analyze architectural approaches

7. Brainstorm and prioritize scenarios

8. Analyze architectural approaches

9. Present results

The first three steps are similar to the QAW presentations made before scenario generation and the QAW presentation of results meetings in that they inform the participants about the process, the techniques used, and the expected outcomes.

The complete ATAM process includes a set of planning steps in a Phase 0 . These steps include negotiations and planning tasks that might take a number of interchanges because they involve scheduling meetings, selecting facilities and participants, and reviewing documents. Phase 0 can extend over a long time and involves multiple interactions with the customers. 
Start

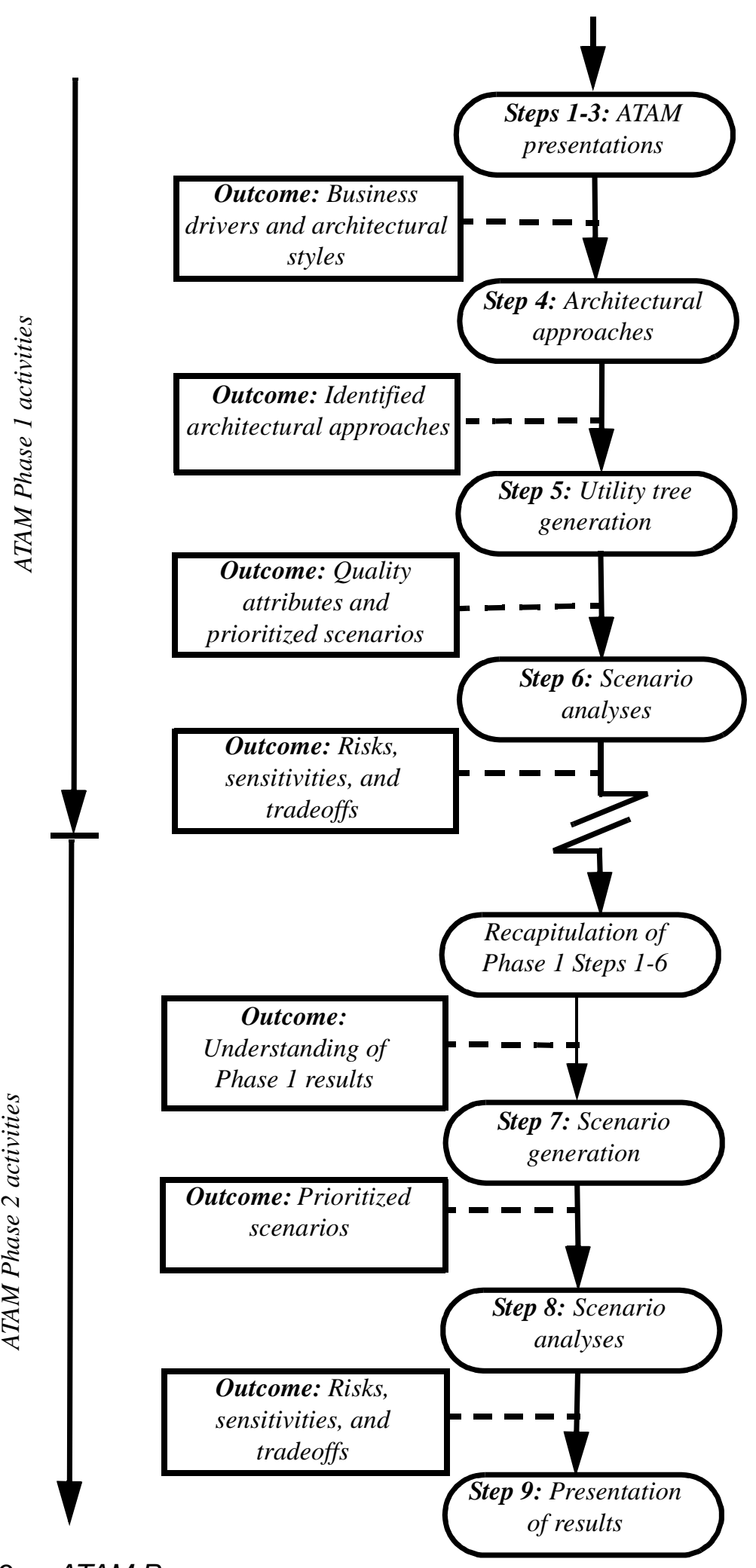

Figure 3: ATAM Process 


\subsection{Phase 1}

In Step 1, the evaluation team presents an overview of the ATAM, including steps, techniques, and expected outputs (such as architectural approaches, a utility tree, scenarios, risks, sensitivity points, and tradeoffs).

In Step 2, a customer representative describes the system's business drivers, including the business context for the system, high-level functional requirements, high-level quality attribute requirements, architectural drivers (quality attributes that "shape" the architecture), and critical requirements (quality attributes that are central to the system's success).

In Step 3, the architect presents an overview of the architecture, including technical constraints (such as an operating system, hardware, or middleware prescribed for use), other systems with which the system must interact, and architectural approaches used to address quality attribute requirements.

In Step 4, the evaluators begin to identify places in the architecture that are key to realizing quality attribute goals; they also identify predominant architectural approaches (some examples include client-server, 3-tier, watchdog, publish-subscribe, and redundant hardware).

In Step 5, the participants identify, prioritize, and refine the most important quality attribute goals by building a utility tree. A utility tree is a top-down vehicle for characterizing the "driving" attribute-specific requirements. The most important quality goals are the high-level nodes -typically performance, modifiability, security, and availability. Scenarios are the leaves of the utility tree, as illustrated in Figure 4.

Scenarios are used to represent stakeholders' interests and should cover a range of anticipated uses of the system (use case scenarios), anticipated changes to the system (growth scenarios), or unanticipated stresses to the system (exploratory scenarios). A good scenario clearly indicates which stimulus causes it and what responses are important. During scenario prioritization, scenarios are categorized by two parameters, importance and difficulty, using a scale of Low (L)-Medium (M)-High (H).

In Step 6, the evaluation team probes architectural approaches to identify risks, sensitivity points, and tradeoffs for specific quality attributes. A risk is a potentially problematic architectural decision. A sensitivity point is a property of one or more components (and/or component relationships) that is critical for achieving a particular quality attribute response. A tradeoff is a property that affects and is a sensitivity point for more than one attribute. 


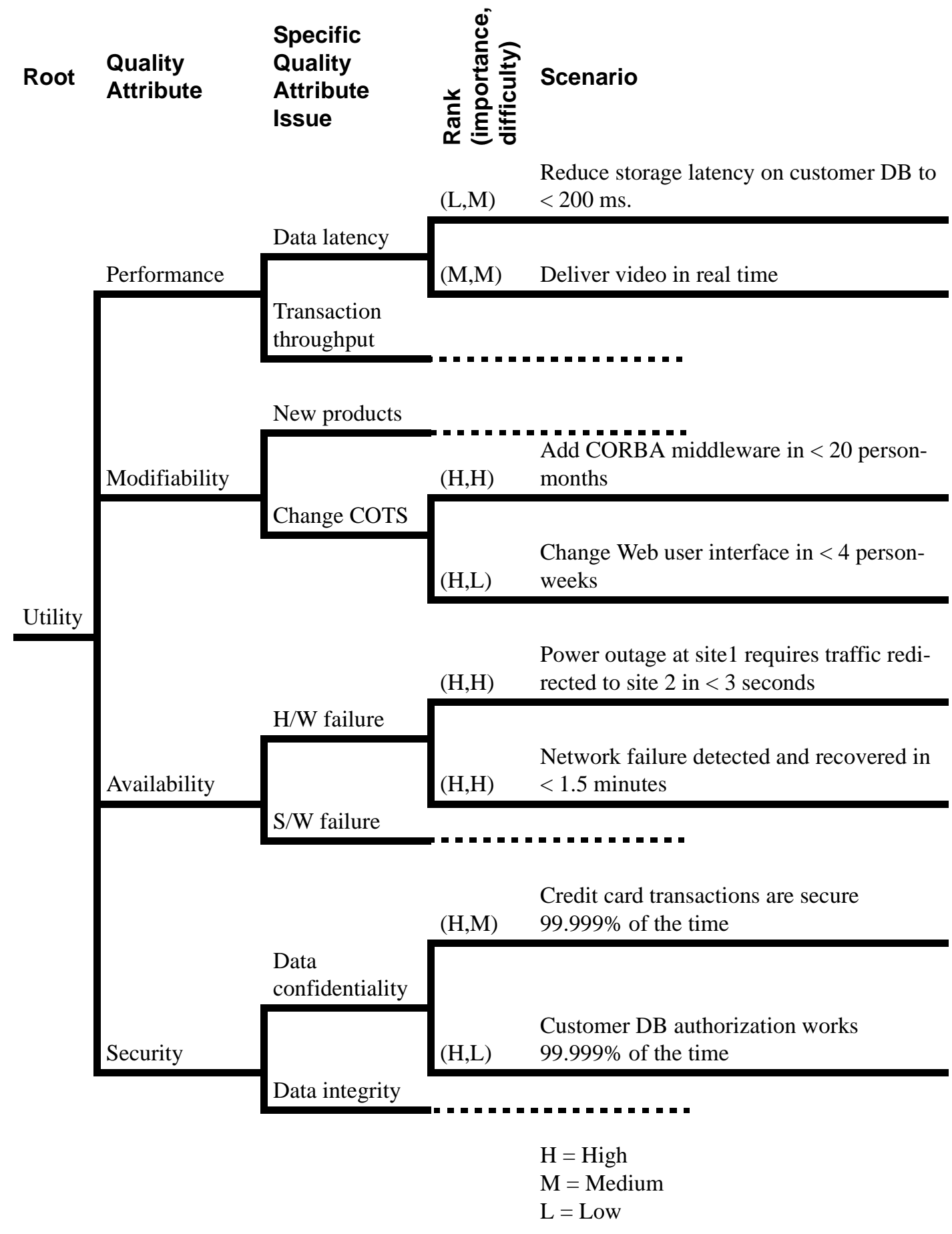

Figure 4: Example ATAM Utility Tree 


\subsection{Phase 2}

At the beginning of the Phase 2 meeting, the evaluation team and some of the participants from the Phase 1 meeting briefly recapitulate the results of the Phase 1 meeting, including the quality attributes and scenarios in the utility tree.

In Step 7, the stakeholders generate and prioritize scenarios using a facilitated brainstorming process. These scenarios are not restricted to the quality attributes listed in the Phase 1 utility tree; rather, they are generated to represent the expanded set of stakeholders' interests. However, the scenarios in the utility tree should not be ignored; these scenarios could be used as example scenarios.

In Step 8, the stakeholders identify the architectural approaches affected by the scenarios generated in Step 7. Step 8 continues the analysis started in Step 6 of Phase 1 using the new scenarios and identifying additional risks, sensitivity points, and tradeoffs.

Finally, in Step 9, the evaluation team presents the ATAM outputs to the stakeholders as confirmation of the architectural approaches, utility tree, scenarios, risks, sensitivity points, and tradeoffs identified during the exercise. 


\section{An Example Application of Both Methods}

There are often contexts in which both the QAW and the ATAM can be used on the same system. Figure 5 illustrates a common United States government acquisition strategy. Starting with an initial request for proposals (RFP), an acquisition organization evaluates proposals from multiple contractors and awards contracts to a small number of contractors to conduct a Competitive Fly-Off. At the end of the Competitive Fly-Off, the contractors submit updated technical proposals, including additional details, and the acquirer makes a Final Down Select.

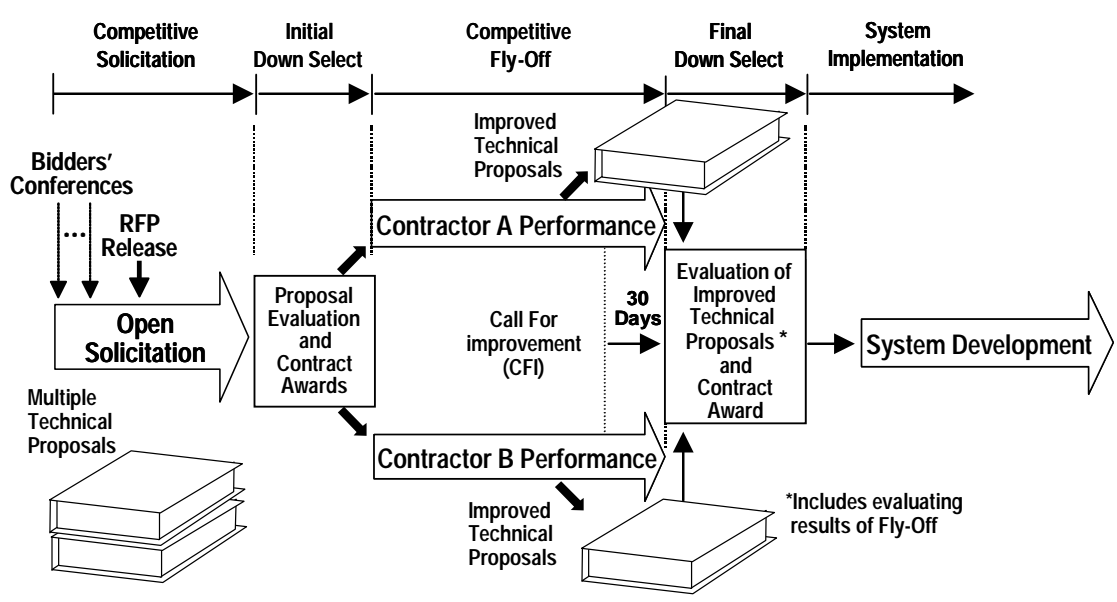

Figure 5: A Common Acquisition Strategy [Bergey 02]

We will use this example to illustrate how QAW and ATAM activities can be combined. In this case, both methods are used during the acquisition process.

\subsection{Activities During the Competitive Solicitation Phase}

Figure 6 shows how QAW activities can be incorporated during the Competitive Solicitation Phase. 
1. One or more QAW scenario generation meetings are conducted with teams from the acquiring organization (e.g., representative groups of stakeholders with similar needs and responsibilities).

2. From these scenarios, the acquiring organization develops a collection of architectural test cases that represent concerns of the stakeholders.

3. Early in the Competitive Solicitation phase and prior to the release of the RFP, the acquirer conducts bidders' conferences to inform potential bidders about the need for conducting architectural analysis.

4. The acquirer drafts sections of the RFP to incorporate architectural analysis requirements and includes the architectural test cases as government-furnished items in the RFP proper.

5. As part of their proposals, bidders are expected to describe how they will conduct the architectural analysis [Bergey 02].

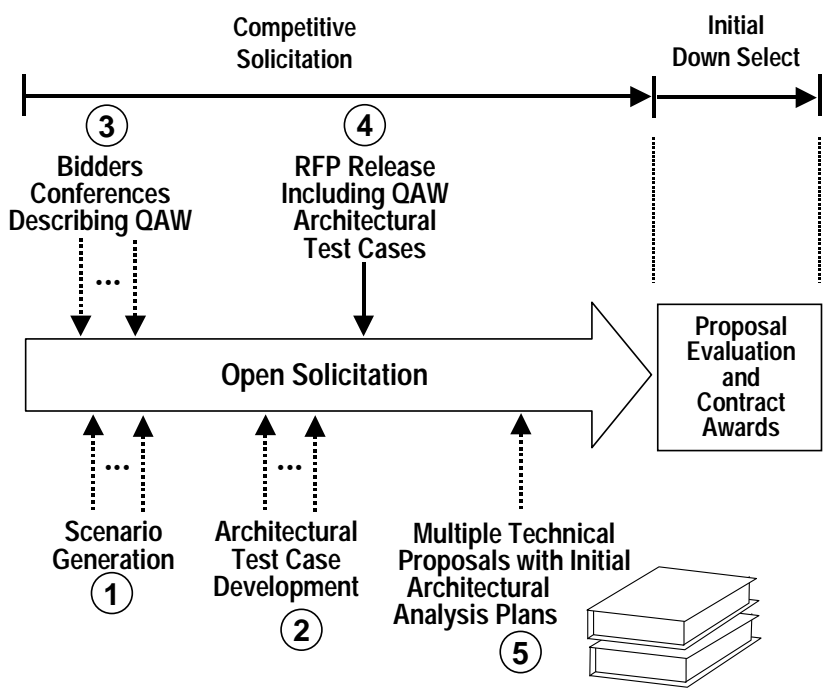

Figure 6: $\quad$ QAW Activities During the Competitive Solicitation Phase 


\subsection{Activities During the Competitive Fly-Off Phase}

Figure 7 shows how QAW activities can be incorporated during the Competitive Fly-Off phase.

1. The contractors analyze their architectures against the architectural test cases and, if necessary, modify their planned architecture.

2. The contractors present the results of their analysis in both a dry-run (rehearsal) as well as a final presentation.

A dry-run presentation should be conducted when the architecture team making the presentation is unsure about any of the following:

- the level of detail required

- the precision expected from its answers to the architectural test case questions

- how to incorporate other analysis results (such as reliability, availability, and maintainability analysis or network-loading analysis)

- what additional architectural documents might be needed

The final presentation takes place after the contractors polish the results of the dry-run presentation.

3. After resolving any potential concerns resulting from the presentation of results, the contractors present their technical proposals to the acquiring organization.

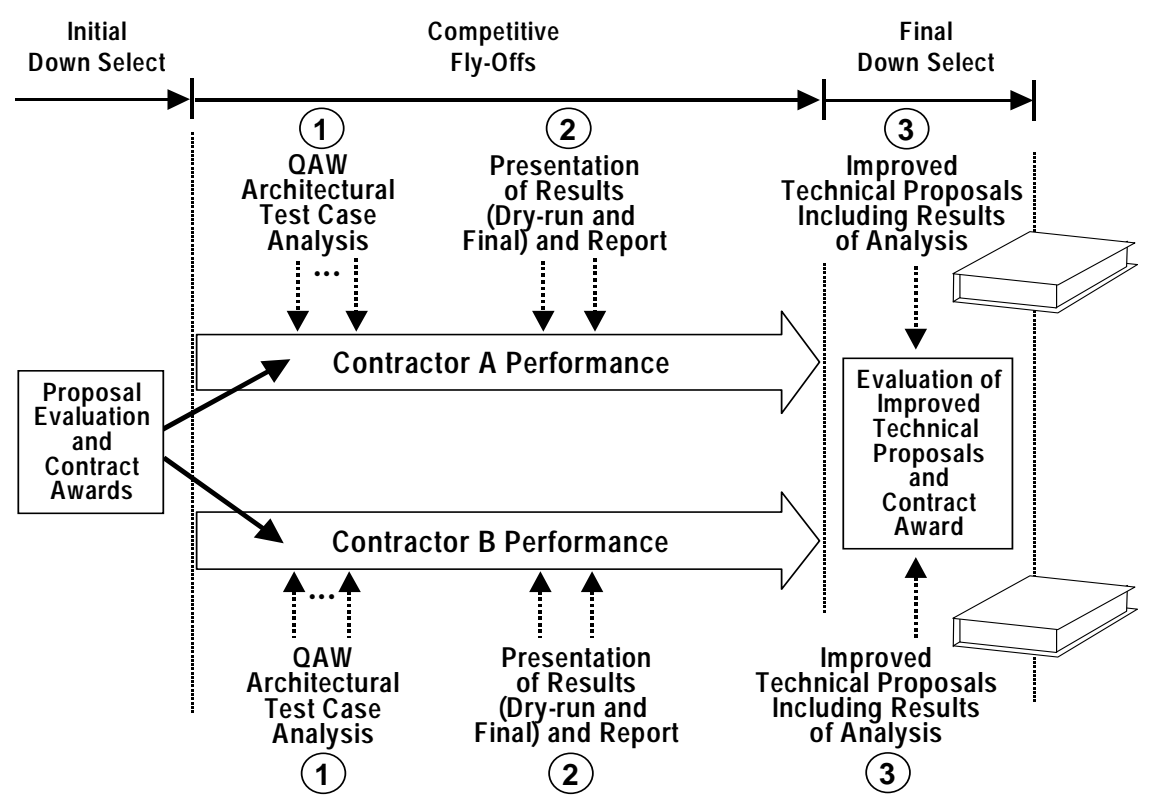

Figure 7: $\quad$ QAW Activities During the Competitive Fly-Off Phase 


\subsection{Activities During the System Implementation Phase}

Figure 8 shows how ATAM activities can be incorporated during the System Implementation phase.

1. The preceding QAW activities have already identified the important quality attribute concerns that can be used to draft the beginning of the utility tree (Step 5 in Phase 1 of the ATAM).

The draft utility tree could be further augmented with "seed scenarios" derived from selected architectural test cases, to determine whether concerns identified during the test case analyses were addressed by the software architecture.

2. ATAM evaluations could be scheduled to fit the development plans, although the results of previous QAW architectural test case analyses might influence the schedule. For example, components or subsystems that were identified as sources of concern to the developers might be subject to ATAM evaluations earlier than other subsystems. These subsystems could also be subject to multiple ATAM evaluations during development.

3. Risks identified during the ATAM evaluations should be addressed during system development.

Depending on the circumstances and the results of the QAW architectural test case analyses, ATAM phases could be customized to allow, for example, one Phase-1 evaluation (involving mostly developers) and multiple Phase-2 evaluations (involving different groups of stakeholders, such as clients or users with different needs). 


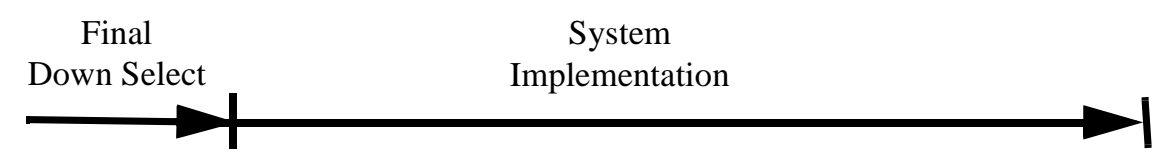

(3) Risk Mitigation Activities

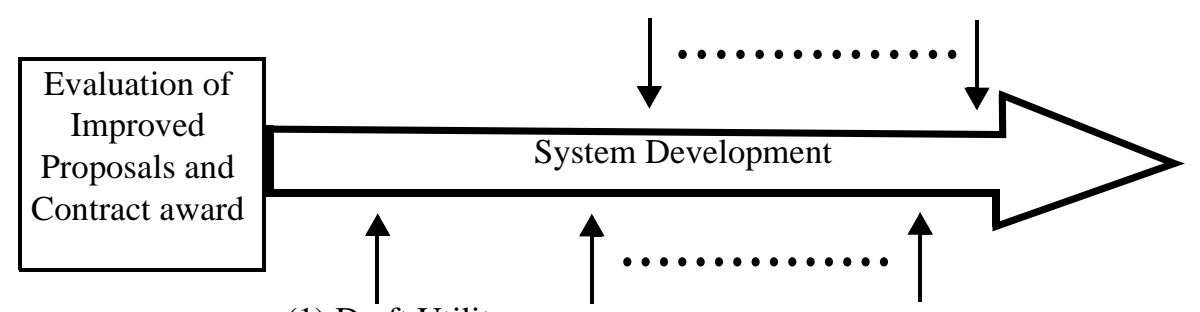

(1) Draft Utility $\quad$ (2) ATAM Evaluations

Tree and

Scenarios from

Selected QAW

Architectural

Test Cases

Figure 8: ATAM Activities During the System Implementation Phase 


\section{Summary Comparison}

Table 3 provides a brief summary of the inputs, outputs, and participants involved in the various QAW activities and ATAM Phases.

\begin{tabular}{|c|c|c|c|c|}
\hline & Inputs & Outputs & Participants & Duration \\
\hline $\begin{array}{l}\text { QAW } \\
\text { Scenario } \\
\text { Generation }\end{array}$ & $\begin{array}{l}\text { QAW presentations } \\
\text { (business drivers, con- } \\
\text { ceptual or system archi- } \\
\text { tecture, quality attribute } \\
\text { requirements) }\end{array}$ & $\begin{array}{l}\text { prioritized, } \\
\text { refined scenar- } \\
\text { ios }\end{array}$ & $\begin{array}{l}\text { system stakeholders } \\
\text { (see presentation of } \\
\text { results). } \\
\text { Depending on the } \\
\text { situation, they may } \\
\text { or may not include } \\
\text { system developers. }\end{array}$ & $\begin{array}{l}\text { one- or two-day } \\
\text { facilitated meet- } \\
\text { ings }\end{array}$ \\
\hline $\begin{array}{l}\text { QAW } \\
\text { Architectural } \\
\text { Test Case } \\
\text { Development }\end{array}$ & $\begin{array}{l}\text { prioritized, refined sce- } \\
\text { narios }\end{array}$ & $\begin{array}{l}\text { architectural } \\
\text { test cases }\end{array}$ & $\begin{array}{l}\text { Depending on the } \\
\text { situation, the partici- } \\
\text { pants might be sys- } \\
\text { tem developers or } \\
\text { acquirers/sponsors. }\end{array}$ & $\begin{array}{l}\text {. . could take } \\
\text { several days }\end{array}$ \\
\hline $\begin{array}{l}\text { QAW } \\
\text { Architectural } \\
\text { Test Case } \\
\text { Analysis }\end{array}$ & architectural test cases & $\begin{array}{l}\text { results of archi- } \\
\text { tectural test case } \\
\text { analysis }\end{array}$ & system developers & $\begin{array}{l}\ldots \text { could take } \\
\text { weeks or } \\
\text { months }\end{array}$ \\
\hline $\begin{array}{l}\text { QAW } \\
\text { Presentation } \\
\text { of Results }\end{array}$ & $\begin{array}{l}\text { results of architectural } \\
\text { test case analysis }\end{array}$ & $\begin{array}{l}\text { additional } \\
\text { results and anal- } \\
\text { ysis report }\end{array}$ & $\begin{array}{l}\text { presentation made } \\
\text { by system develop- } \\
\text { ers to other system } \\
\text { stakeholders (see } \\
\text { scenario generation) }\end{array}$ & $\begin{array}{l}\text { one- or two-day } \\
\text { facilitated meet- } \\
\text { ings }\end{array}$ \\
\hline $\begin{array}{l}\text { ATAM } \\
\text { Phase } 1\end{array}$ & $\begin{array}{l}\text { ATAM Presentations } \\
\text { (business drivers and } \\
\text { architectural approaches) }\end{array}$ & $\begin{array}{l}\text { utility tree, } \\
\text { risks, sensitivi- } \\
\text { ties, and } \\
\text { tradeoffs }\end{array}$ & $\begin{array}{l}\text { sponsors and devel- } \\
\text { opers (technically } \\
\text { oriented stakehold- } \\
\text { ers) }\end{array}$ & $\begin{array}{l}\text { one- or two-day } \\
\text { facilitated meet- } \\
\text { ings }\end{array}$ \\
\hline $\begin{array}{l}\text { ATAM } \\
\text { Phase } 2\end{array}$ & $\begin{array}{l}\text { ATAM Presentations } \\
\text { (business drivers and } \\
\text { architectural } \\
\text { approaches); } \\
\text { results from Phase } 1 \\
\text { (utility tree, risks, sensi- } \\
\text { tivities, and tradeoffs) }\end{array}$ & $\begin{array}{l}\text { results from } \\
\text { Phase 1, addi- } \\
\text { tional scenar- } \\
\text { ios, risks, } \\
\text { sensitivities, } \\
\text { and tradeoffs }\end{array}$ & $\begin{array}{l}\text { sponsors, develop- } \\
\text { ers, and other stake- } \\
\text { holders (such as } \\
\text { customers, users, } \\
\text { maintainers) }\end{array}$ & $\begin{array}{l}\text { one- or two-day } \\
\text { facilitated meet- } \\
\text { ings }\end{array}$ \\
\hline
\end{tabular}

Table 3: $\quad$ QAW and ATAM Inputs, Outputs, and Participants for Various Activities 
References

all URLs valid as of the publication date of this document

[Barbacci 02] Barbacci, M.; Ellison, R.; Lattanze, A.; Stafford, J.; Weinstock, C.; \& Wood, W. Quality Attribute Workshops, 2nd Edition (CMU/ SEI-2002-TR-019, ADA405790). Pittsburgh, PA: Software Engineering Institute, Carnegie Mellon University, 2002.

$<$ http://www.sei.cmu.edu/publications/documents /02.reports/02tr019.html>.

[Bergey 02]

Bergey, J. \& Wood, W. Use of Quality Attribute Workshops (QAWs) in Source Selection for a DoD System Acquisition: A Case Study (CMU/SEI-2002-TN-013, ADA405848). Pittsburgh, PA: Software Engineering Institute, Carnegie Mellon University, 2002. <http://www.sei.cmu.edu/publications/documents /02.reports/02tn013.html>.

[Clements 01]

Clements, P.; Kazman, R.; \& Klein, M. Evaluating Software Architectures: Methods and Case Studies. Boston, MA: AddisonWesley, 2001.

[Kazman 00]

Kazman, R.; Klein, M.; \& Clements, P. ATAM: Method for Architecture Evaluation (CMU/SEI-2000-TR-004, ADA382629).

Pittsburgh, PA: Software Engineering Institute, Carnegie Mellon University, 2000. <http://www.sei.cmu.edu/publications /documents/00.reports/00tr004.html .

[SEI 02]

Software Engineering Institute.Software Architecture and the Architecture Tradeoff Analysis Initiative.

$<$ http://www.sei.cmu.edu/ata/ata_init.html >. 


\begin{tabular}{|c|c|c|c|c|c|}
\hline \multicolumn{4}{|c|}{ REPORT DOCUMENTATION PAGE } & \multirow{2}{*}{\multicolumn{2}{|c|}{ 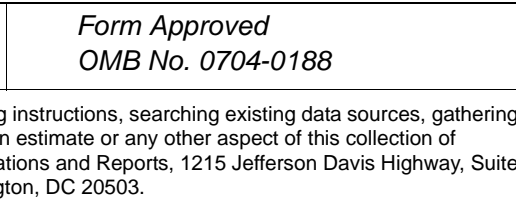 }} \\
\hline \multicolumn{4}{|c|}{ 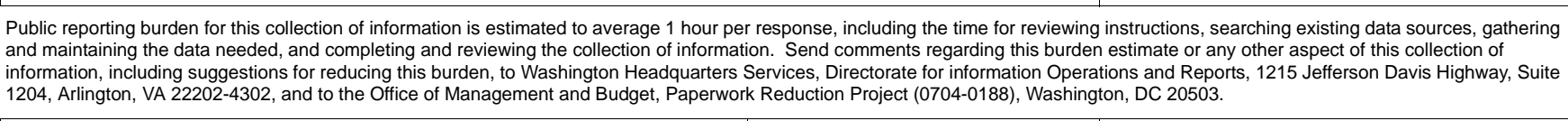 } & & \\
\hline 1. & \multicolumn{2}{|c|}{ AGENCY USE ONLY (leave blank) } & $\begin{array}{ll}\text { 2. } & \text { REPORT DATE } \\
& \text { October } 2002\end{array}$ & 3. & $\begin{array}{l}\text { REPORT TYPE AND DATES COVERED } \\
\text { Final }\end{array}$ \\
\hline 4. & \multicolumn{3}{|c|}{$\begin{array}{l}\text { TITLE AND SUBTITLE } \\
\text { SEI Architecture Analysis Techniques and When to Use Them }\end{array}$} & & \multirow[t]{2}{*}{$\begin{array}{l}\text { FUNDING NUMBERS } \\
\text { C - F19628-00-C-0003 }\end{array}$} \\
\hline & \multicolumn{3}{|l|}{$\begin{array}{l}\text { AUTHOR(s) } \\
\text { Mario Barbacci }\end{array}$} & & \\
\hline & \multicolumn{3}{|c|}{$\begin{array}{l}\text { PERFORMING ORGANIZATION NAME(S) AND ADDRESS(ES) } \\
\text { Software Engineering Institute } \\
\text { Carnegie Mellon University } \\
\text { Pittsburgh, PA } 15213\end{array}$} & & $\begin{array}{l}\text { PERFORMING ORGANIZATION } \\
\text { REPORT NUMBER } \\
\text { CMU/SEI-2002-TN-005 }\end{array}$ \\
\hline & \multicolumn{3}{|c|}{$\begin{array}{l}\text { SPONSORING/MONITORING AGENCY NAME(S) AND ADDRESS(ES) } \\
\text { HQ ESC/XPK } \\
5 \text { Eglin Street } \\
\text { Hanscom AFB, MA 01731-2116 }\end{array}$} & \multicolumn{2}{|c|}{$\begin{array}{ll}10 . & \text { SPONSORING/MONITORING } \\
\text { AGENCY REPORT NUMBER }\end{array}$} \\
\hline \multicolumn{6}{|c|}{ 1. SUPPLEMENTARY NOTES } \\
\hline \multicolumn{4}{|c|}{$\begin{array}{l}\text { 2.a DISTRIBUTION/AVAILABILITY STATEMENT } \\
\text { Unclassified/Unlimited, DTIC, NTIS }\end{array}$} & \multicolumn{2}{|c|}{ 12.b DISTRIBUTION CODE } \\
\hline & \multicolumn{5}{|c|}{$\begin{array}{l}\text { ABSTRACT (maximum } 200 \text { words) } \\
\text { The Software Engineering Institute (SEI }{ }^{S M} \text { ) has developed two methods for analyzing system and software } \\
\text { architectures-the Quality Attribute Workshop (QAW) and the Architecture Tradeoff Analysis Method } \\
\text { (ATAM }{ }^{S M} \text { ). These techniques, which are described in detail in various SEI technical reports and on the SEI } \\
\text { Web site, can be used in combination to obtain early and continuous benefits. Designed to complement the } \\
\text { ATAM, the QAW provides a method for analyzing a conceptual architecture or a system architecture against } \\
\text { a number of critical quality attributes-such as availability, performance, security, interoperability, and } \\
\text { modifiability-before the software architecture is fully developed. Once the software architecture is } \\
\text { developed, the ATAM can be used to reveal how well the architecture satisfies particular quality attribute } \\
\text { requirements and the risks, sensitivities, and tradeoffs involved in satisfying the requirements. }\end{array}$} \\
\hline & \multicolumn{5}{|c|}{$\begin{array}{l}\text { The purpose of this technical note is to describe, using a hypothetical example, the alignment, combination, } \\
\text { and uses of the two methods. }\end{array}$} \\
\hline \multirow[t]{3}{*}{14.} & \multicolumn{3}{|l|}{ SUBJECT TERMS } & \multirow[t]{2}{*}{15.} & NUMBER OF PAGES \\
\hline & \multirow{2}{*}{\multicolumn{3}{|c|}{$\begin{array}{l}\text { Quality Attribute Workshop, QAW, Architecture Tradeoff Analysis Method, } \\
\text { ATAM, architecture analysis }\end{array}$}} & & 32 \\
\hline & & & & & PRICE CODE \\
\hline \multirow[t]{2}{*}{17.} & $\begin{array}{l}\text { SECURITY CLASSIFICATION } \\
\text { OF REPORT } \\
\text { UNCLASSIFIED }\end{array}$ & $\begin{array}{l}\text { 18. SECURITY CLASSIFICATION } \\
\text { OF THIS PAGE } \\
\text { UNCLASSIFIED }\end{array}$ & $\begin{array}{ll}19 . & \text { SECURITY } \\
\text { CLASSIFICATION } \\
\text { OF ABSRACT } \\
\\
\text { UNCLASSIFIED }\end{array}$ & \multicolumn{2}{|c|}{$\begin{array}{l}\text { 20. LIMITATION OF ABSTRACT } \\
\text { UL }\end{array}$} \\
\hline & $540-01-280-5500$ & & & $\begin{array}{l}\text { Standar } \\
\text { Prescribe } \\
298-102\end{array}$ & $\begin{array}{l}\text { orm } 298 \text { (Rev. 2-89) } \\
\text { ANSI Sto. Z39-18 }\end{array}$ \\
\hline
\end{tabular}


